$1-19-2021$

\title{
Relationship Between Physician Burnout and Patient's Perception of Bedside Time Spent by Physicians
}

\author{
Shannon Leung \\ Mukta Panda \\ Georgia McIntosh \\ Nargiza Kurbanova \\ Anna-Carson Rimer Uhelski \\ Muhammad Mubbashir Sheikh \\ Rehan Qayyum
}

Follow this and additional works at: https://aah.org/jpcrr

Part of the Behavioral Medicine Commons, Health Services Research Commons, Internal Medicine Commons, Other Mental and Social Health Commons, Other Social and Behavioral Sciences Commons, and the Psychiatric and Mental Health Commons

\section{Recommended Citation}

Leung S, Panda M, McIntosh G, Kurbanova N, Rimer Uhelski AC, Sheikh MM, Qayyum R. Relationship between physician burnout and patient's perception of bedside time spent by physicians. J Patient Cent Res Rev. 2021;8:58-63. doi: 10.17294/2330-0698.1764

Published quarterly by Midwest-based health system Advocate Aurora Health and indexed in PubMed Central, the Journal of Patient-Centered Research and Reviews (JPCRR) is an open access, peer-reviewed medical journal focused on disseminating scholarly works devoted to improving patient-centered care practices, health outcomes, and the patient experience. 


\title{
Relationship Between Physician Burnout and Patient's Perception of Bedside Time Spent by Physicians
}

\author{
Shannon Leung, BS, ${ }^{1}$ Mukta Panda, MD, ${ }^{2}$ Georgia Mclntosh, MD, ${ }^{1}$ Nargiza Kurbanova, BSN, ${ }^{1}$ \\ Anna-Carson Rimer Uhelski, MD, ${ }^{2,3}$ Muhammad Mubbashir Sheikh, MD, ${ }^{2}$ Rehan Qayyum, MD, MHS ${ }^{1}$ \\ ${ }^{1}$ Division of Hospital Medicine, Virginia Commonwealth University School of Medicine, Richmond, VA; ${ }^{2}$ University of \\ Tennessee College of Medicine Chattanooga, Chattanooga, TN; ${ }^{3}$ Johns Hopkins Hospital, Baltimore, MD
}

\begin{abstract}
Although the adverse effect of burnout on physicians has been widely documented, studies have shown an inconsistent relationship between burnout and the quality of patient care. We hypothesized that physician burnout will have an inverse relationship with the time spent at the bedside by physicians. In a cross-sectional study, we surveyed patients on their perception of the time spent by their physician on the day of the survey (4 categories: $0-5,6-10,11-15,>15$ minutes). Oldenburg Burnout Inventory was used to assess physician burnout; burnout was defined as high levels of both exhaustion $(\geq 2.25)$ and disengagement $(\geq 2.10)$. Among the 1374 patients, the most commonly reported time spent at bedside category was 6-10 minutes ( $n=614,45 \%$ ). Among the 95 physicians who saw these patients, burnout was present in $44(46 \%)$, with a higher prevalence in women $(61 \%$ vs $39 \% ; \mathrm{P}=0.04)$. Using ordered logistic regression, we found no relationship between physician burnout and patient's perception of bedside time spent, without adjustment (odds ratio: $0.86,95 \% \mathrm{Cl}$ : 0.65-1.16) or with adjustment (odds ratio: $0.85,95 \% \mathrm{Cl}$ : $0.64-1.12$ ) for potential confounders. Although physician burnout is not associated with patient perception of time spent at bedside, it may be associated with other patient outcomes that require further research. (J Patient Cent Res Rev. 2021;8:58-63.)
\end{abstract}

Keywords patient satisfaction; physician burnout; patient perception; time spent; bedside

$\mathrm{P}$ hysician burnout has become a widespread epidemic in health care, affecting about $50 \%$ of physicians in the United States, in all stages of their medical career, in all practice settings, and in all specialties. ${ }^{1-3}$ Burned-out physicians have a twofold higher risk of leaving the institution, with turnover replacement and reduced productivity costing $\$ 4.6$ billion annually in the United States. ${ }^{4}$ In addition to the financial impact, burned-out physicians have higher rates of drug and alcohol use, depression, and suicidal ideation in comparison to physicians without burnout..$^{5-7}$

Depending on the conceptual framework, burnout may be defined by two domains, disengagement and exhaustion, or by three domains, the third being personal achievement. ${ }^{8}$ Factors that mitigate burnout include organizational factors such as practice environment, rules and regulations, and personal factors such as autonomy, competence, and interpersonal connection. ${ }^{9}$ Although adverse effects of burnout on physicians have been

Corresponding author: Rehan Qayyum, MD, MHS, SFHM, FAHA, 1200 E. Marshall Street, Sanger Hall, Room 1-010F, Richmond, VA 23298 (rqayyum@vcu.edu) widely documented, the relationship between physician burnout and patient care quality remains unclear. Studies have found that physicians with higher levels of burnout perceived themselves to make significantly more medical errors; ${ }^{10,11}$ however, there was no relationship when studies examined the rate of medical errors objectively. ${ }^{12,13}$ Similarly, studies examining the relationship of physician burnout with patient-reported satisfaction have yielded contradictory results. ${ }^{14-16}$

Patient's perception of the quality of care is important, as shown by strong correlations between patient-reported satisfaction with their physicians and patient outcomes. ${ }^{17,18}$ In addition, longer time spent at bedside by physicians has been associated with higher patient satisfaction. . $^{1920}$ Therefore, we hypothesized and examined whether a patient's perception of the time spent by physicians at bedside is associated with physician burnout.

\section{METHODS}

A cross-sectional study, using 2 independent surveys and enrolling hospitalized patients and their treating physicians at 2 tertiary academic medical centers located in Tennessee and Virginia, was conducted. The study and its methods were approved by the respective institutional review boards. 
In the first survey, patients were included if they were hospitalized for at least 2 days, were 18 years of age or older, spoke English, and agreed to participate. Patients were approached at least 2 days after hospitalization to allow them to get familiar with their health care team. English-speaking status of a patient was determined by the patient's health care team. Patients with altered mental status or dementia or those who were clinically unstable were excluded. Patients were approached by a study investigator for participation during the second half of the day, and each patient was approached only once during hospitalization. Patients were asked to identify their primary treating physician prior to participation and were excluded if they could not identify the physician.

Using the survey tool, we collected nonidentifying demographic information and patients' perception of the time spent by physicians at bedside on the day of survey or a day prior if primary attending had not visited the patient by the time of the survey. Bedside time spent was measured with only 1 question on the survey: "How much time did your physician spend with you today?" Patients chose from 1 of 4 categories: 1) between 0 and 5 minutes; 2) between 6 and 10 minutes; 3) between 11 and 15 minutes; or 4) more than 15 minutes. These time categories were chosen to allow for easier patient response to the survey.

In the second survey, physician burnout was measured using the Oldenburg Burnout Inventory (OBI), ${ }^{8}$ which is a 16-item questionnaire that measures burnout on 2 domains: disengagement and exhaustion. Each domain consists of 8 items, and each item has 4 response choices. All internal medicine physicians with admitting privileges at the hospitals were eligible for the study. Physician participants were emailed the OBI survey with demographic questions; completion of the survey was considered consent for participation.

Data from both surveys were merged to generate the dataset for analysis. Mean (standard deviation), median (interquartile range), or frequencies were used for descriptive statistics as appropriate. Based on the recommendations of the OBI authors, we used the 2 burnout domains separately in models as continuous variables. Because burnout is commonly conceptualized as a dichotomous variable, we used previously defined cutoff values for the 2 domains: exhaustion score of $\geq 2.25$ and disengagement score of $\geq 2.10{ }^{21}$ Using these cutoffs values, we defined burnout in 4 additional ways: 1) exhaustion only versus no exhaustion (BOEX); 2) disengagement only versus no disengagement (BODE); 3) burnout in exhaustion and/or disengagement domains versus no burnout in any domain (BOAD); and 4) burnout in both domains versus no burnout or burnout in one domain only (BOBD).

To compare study population characteristics by burnout status, two-tailed $t$-test or one-way ANOVA was used for continuous variables and Pearson's chi-squared test for categorical variables. Due to the ordinal nature of the dependent variable, the patient's perception of time spent by physicians at bedside, ordered logistic regression was used. We specified the variance-covariance matrix to allow for the correlation between observations from the same physician. ${ }^{22}$ Analyses were conducted without and with adjustment for the following potential confounders: patient age, patient gender, patient race, physician race, and physician gender. A P-value of $<0.05$ was considered statistically significant. All analyses were conducted using Stata 15 software (StataCorp LLC).

\section{RESULTS}

Of the 1374 patients who participated in the study, 708 $(53 \%)$ were female and 1050 (79\%) were Caucasian; mean age was 54.1 (16.7) years (Table 1). Time spent by physicians was perceived between 6 and 10 minutes by 614 (45\%) patients, between 11 and 15 minutes by 288 (21\%) patients, $>15$ minutes by $252(18 \%)$ patients, and between 0 and 5 minutes by $220(16 \%)$ patients. There was no difference in the perceptions of time spent by patient age, race, or gender (Table 2).

The enrolled patients were seen by 95 unique physicians who also completed the survey. Of these physicians, $31(33 \%)$ were female and $66(69 \%)$ were Caucasian. Mean physician exhaustion score was $2.41(0.52)$, and mean physician disengagement score was $2.25(0.49)$. Mean exhaustion and disengagement scores were similar between male and female physicians $(2.40$ vs 2.41 $[\mathrm{P}=0.95]$ and 2.21 vs $2.34[\mathrm{P}=0.25]$, respectively) and between Caucasian and non-Caucasian physicians $(2.47$ vs $2.31[\mathrm{P}=0.18]$ and 2.30 vs $2.20[\mathrm{P}=0.39]$, respectively). BOEX was present in $53(56 \%)$, BODE in $68(72 \%)$, BOAD in 77 (81\%), and BOBD in $44(46 \%)$ physicians. Women had higher rates of BOBD than men $(61.3 \%$ vs $39.1 \%$ [P=0.04]; Table 1).

Because patient enrollment was independent of physician enrollment in the study, we expected to find the proportion of patients seen by burnout physicians to be similar to the proportion of physicians with burnout. However, the proportion of patients seen by physicians with burnout was lower than the proportion of patients seen by physicians without burnout ( $42.5 \%$ vs $46.3 \%$ [P=0.005]; Table 1 ).

The relationship between the patient's perception of time spent by physician and burnout was examined by 
Table 1. Study Population Characteristics by the Presence of Physician Burnout in Both Domains

\begin{tabular}{|c|c|c|c|}
\hline Participant group & No burnout ${ }^{\mathrm{a}}$ & Burnout $^{\mathrm{a}}$ & $\boldsymbol{P}$ \\
\hline Physicians (N=95), n (\%) & $51(53.7 \%)$ & $44(46.3 \%)$ & 0.47 \\
\hline Female, n (\%) & $12(23.5 \%)$ & $19(41.9 \%)$ & 0.04 \\
\hline Caucasian, n (\%) & $32(65.3 \%)$ & $34(76.7 \%)$ & 0.12 \\
\hline Exhaustion score, mean (standard deviation) & $2.07(0.41)$ & $2.80(0.33)$ & $<0.001$ \\
\hline Disengagement score, mean (standard deviation) & $1.98(0.37)$ & $2.57(0.45)$ & $<0.001$ \\
\hline Patients (N=1374), n (\%) & $790(57.5 \%)$ & $584(42.5 \%)$ & $0.005^{b}$ \\
\hline Age, mean (standard deviation) & $54.1(16.7)$ & $54.0(16.6)$ & 0.94 \\
\hline Female, $\mathrm{n}(\%)$ & $397(52.2 \%)$ & $311(54.3 \%)$ & 0.44 \\
\hline Caucasian, n (\%) & $598(78.6 \%)$ & $452(78.9 \%)$ & 0.89 \\
\hline
\end{tabular}

aPhysician burnout for this table was defined as burnout in both domains, with cutoff values of $\geq 2.25$ for exhaustion score and $\geq 2.10$ for disengagement score.

${ }^{b}$ The null hypothesis here is that the proportion of patients seen by burned-out physicians (42.5\%) is the same as the proportion of burnout among physicians (46.3\%).

Table 2. Patient Perception of Physician Time Spent at Bedside, by Patient Characteristics, Oldenburg Burnout Inventory Score, and Presence of Physician Burnout

\begin{tabular}{|c|c|c|c|c|c|}
\hline Variable & 0-5 minutes & $6-10$ minutes & $11-15$ minutes & $>15$ minutes & $\boldsymbol{P}$ \\
\hline Patients (N=1374) & $220(16.0 \%)$ & $614(44.7 \%)$ & $288(21.0 \%)$ & $252(18.3 \%)$ & $<0.001^{\mathrm{a}}$ \\
\hline Patient age, mean (SD) & $52.7(18.4)$ & $53.6(16.2)$ & $55.6(16.6)$ & $54.6(16.1)$ & 0.22 \\
\hline Female patients, n (\%) & $111(51.4 \%)$ & $312(52.6 \%)$ & $149(53.4 \%)$ & $136(55.3 \%)$ & 0.85 \\
\hline Patient race, n (\%) & $177(82.3 \%)$ & $472(79.6 \%)$ & $218(77.6 \%)$ & $183(74.7 \%)$ & 0.21 \\
\hline \multicolumn{6}{|l|}{ Seen by 95 physicians withb: } \\
\hline Exhaustion score, mean (SD) & $2.48(0.64)$ & $2.40(0.69)$ & $2.40(0.64)$ & $2.37(0.59)$ & 0.35 \\
\hline Disengagement score, mean (SD) & $2.33(0.68)$ & $2.27(0.68)$ & $2.23(0.63)$ & $2.23(0.62)$ & 0.30 \\
\hline BOEX, n (\%) & $119(54.1 \%)$ & $292(47.6 \%)$ & $141(49.0 \%)$ & $130(51.6 \%)$ & 0.35 \\
\hline BODE, n (\%) & $126(57.3 \%)$ & $332(54.1 \%)$ & $152(52.8 \%)$ & $136(54.0 \%)$ & 0.78 \\
\hline BOAD, n (\%) & $138(62.7 \%)$ & $370(60.3 \%)$ & $172(59.7 \%)$ & $164(65.1 \%)$ & 0.52 \\
\hline BOBD, n (\%) & $107(48.6 \%)$ & $254(41.4 \%)$ & $121(42.0 \%)$ & $102(40.5 \%)$ & 0.24 \\
\hline
\end{tabular}

${ }^{a}$ Chi-squared goodness of fit test.

${ }^{b}$ Exhaustion was measured as continuous variable, disengagement as continuous variable, BOEX as dichotomous variable (burnout based on exhaustion at cutoff of $\geq 2.25$ ), BODE as dichotomous variable (burnout based on disengagement at cutoff of $\geq 2.10)$, BOAD as burnout in either the exhaustion or disengagement domain, and BOBD as burnout in both exhaustion and disengagement domains.

$B O A D$, exhaustion only versus no exhaustion; $B O B D$, burnout in both domains versus no burnout or burnout in one domain only; BODE, disengagement only versus no disengagement; BOEX, exhaustion only versus no exhaustion; SD, standard deviation.

separately modeling the 2 OBI domains of burnout as well as the 4 dichotomous variables ( 6 models, 1 each for 6 burnout variables). Despite defining burnout in these different ways, we did not see a relationship between any definition of burnout and patient's perception of time spent without or with adjustment for potential confounders
(Figure 1). Further, none of the other variables in the adjusted model were associated with time spent by physicians except one; Caucasian patients reported that physicians spent less time with them $(\mathrm{P}<0.05$ in all multivariable ordered logistic regression models; see Online Supplemental Table S1). 
Odds Ratio (95\% CI) P-value

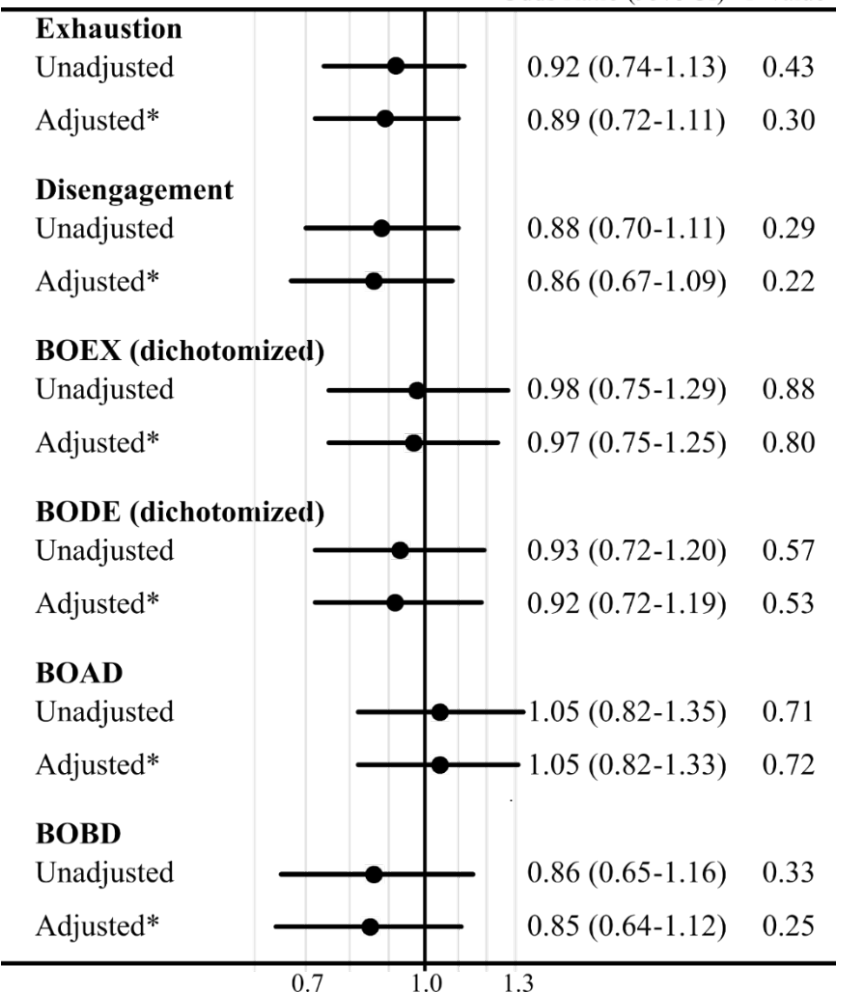

Figure 1. Unadjusted and adjusted multivariable analysis of burnout outcomes with patient's perception of time spent. Adjusted confounders included patient age, gender, and race as well as physician gender and race. Odds ratios are for being in a higher category of patient perception of time spent. Burnout was measured using Oldenburg Burnout Inventory. Exhaustion was measured as continuous variable, disengagement as continuous variable, BOEX as dichotomous variable (burnout based on exhaustion at cutoff of $\geq 2.25$ ), BODE as dichotomous variable (burnout based on disengagement at cutoff of 22.10), BOAD as burnout in either the exhaustion or disengagement domain, and BOBD as burnout in both exhaustion and disengagement domains. $B O A D$, exhaustion only versus no exhaustion; $B O B D$, burnout in both domains versus no burnout or burnout in one domain only; BODE, disengagement only versus no disengagement; BOEX, exhaustion only versus no exhaustion.

\section{DISCUSSION}

In this study, a patient's perception of the time spent by hospital physicians at bedside was not associated with physician burnout. This lack of association was present even when burnout was defined using various definitions and after adjusting for potential confounding effects of patient-level and physician-level demographic factors. While large variation was present in patient perception of time spent at bedside by physicians, lack of its association with burnout suggests that factors other than physician burnout are important determinants of this variation. Furthermore, this study validated the current literature's findings of high prevalence of burnout among physicians in general and a higher prevalence of burnout among female than male physicians. ${ }^{23}$

Physicians with high levels of burnout are expected to spend less time at bedside due to high exhaustion and disengagement. Conversely, spending significant amounts of time at the bedside may result in increased burnout among physicians due to high patient-care needs or in decreased burnout due to higher interpersonal connectedness. Irrespective of what direction the hypothesized causal pathway takes, one would expect to see a direct or inverse relationship between burnout and time spent by physicians at bedside. The mechanism underlying the surprising finding in this study of no relationship between burnout and time spent remains unclear. One likely explanation is that physicians are highly trained individuals who, despite feeling burned out, take their professional responsibilities as the highest priority. Thus, physicians maintain a high level of professionalism and continue to exhibit a strong work ethic and therefore their patients do not perceive any difference in bedside time regardless of burnout level. ${ }^{15,24}$

Furthermore, this study also reported that physicians with burnout attended fewer patients than physicians without burnout. While investigation of underlying mechanisms for this association was beyond the scope of the work presented herein, we speculate that physicians with smaller patient-facing workload may have other nonclinical responsibilities and that such nonclinical work might be a risk factor for physician burnout. Conversely, it is also possible that burnout is the initiating factor that leads physicians to commit to a smaller patient load. In addition, patient perception may be influenced by other variables outside of the physician's control, such as the patient's total length of stay, the severity of patient illness, and the presence or absence of visitors in the patient room. ${ }^{25-28}$

While the current literature is consistent in documenting burnout's adverse relationship with institutional financial costs, physician well-being, and medical errors, the association of physician burnout with patient-perceived outcomes remains inconsistent. ${ }^{1,-6,12,13}$ To our knowledge, this is the first study to examine the relationship between patient-perceived time spent by physicians at bedside and physician burnout. Studies that utilized another patientperceived outcome, patient satisfaction, have reported conflicting results. ${ }^{15-17}$ Our study extends the existing knowledge by showing that physician burnout, while 
affecting physicians themselves adversely, does not affect the patient's perceptions of care provided by those physicians.

Although several important implications stem from the results of this study, the most important is in the clinical care of patients. Our findings are likely reassuring for patients and their families in that, despite high levels of burnout, physicians continue to spend the same amount of time with patients as they would in the absence of burnout. The findings also may be reassuring to physicians, suggesting they have been able to keep a high level of professionalism while facing burnout. Notably, this study highlights the importance of objective measurement of outcomes in physician burnout research to determine the extent to which burnout affects patientreported outcomes.

\section{Limitations}

This study has several strengths and limitations. A large number of patients were enrolled, and each physician had multiple patients to obtain a reliable estimate of time spent at bedside. Patients and physicians were from two different academic centers in two different states, which increases the generalizability of our findings, though further study in diverse settings is needed to determine if results are generalizable to other specialties or countries. Data were collected at one point in time, therefore, the within-patient effects of variation in burnout on time spent at bedside cannot be determined. There remains a risk for residual confounding, as we did not collect information on some physician demographic variables such as age. Further, a causal interpretation from the results is difficult without strong assumptions, due to the crosssectional study design. We did not adjust for the severity of patient illness. All participants were non-critical care patients and were able to answer study questions. While a patient's severity of illness is likely associated with the time spent by physician at bedside, severity of illness is unlikely to be associated with distribution of patients to physicians taking care of non-critical care patients with or without burnout. We excluded patients who could not identify their treating physician. One possible reason that patients might not be able to identify their treating physician could be that burned-out physicians may not engage with their patients well enough for patients to know them well. However, having multiple observations on most physicians should have mitigated this limitation.

In summary, our study found no association between physician burnout and patient perception of time spent at bedside by physicians. Future research is needed to understand the relationship between quality of patient care and physician burnout. With the prevalence of physician burnout on the rise, possible prevention and treatment of burnout, as well as its impact on patient outcomes, warrants continued assessment.

\section{Patient-Friendly Recap}

- Physician burnout is a widespread concern in the health care industry given its already strained workforce. Burnout's potential effect on patient outcomes remains unclear.

- The authors surveyed both physicians and patients, the first group to determine degree of individual burnout and the second group to measure the perceived time spent at their bedside by their treating physicians.

- They found that physicians who report being burned out do not appear to spend less time with their patients. Further research is needed to confirm these results in other settings and to examine quality of care by physicians with burnout.

\section{Author Contributions}

Study design: Panda, McIntosh, Kurbanova, Qayyum. Data acquisition or analysis: all authors. Manuscript drafting: Leung, Panda, McIntosh, Kurbanova, Qayyum. Critical revision: Panda, McIntosh, Kurbanova, Rimer Uhelski, Sheikh, Qayyum.

\section{Conflicts of Interest}

None.

\section{References}

1. Dyrbye LN, West CP, Satele D, et al. Burnout among U.S. medical students, residents, and early career physicians relative to the general U.S. population. Acad Med. 2014;89:443-51. CrossRef

2. Linzer M, Visser MR, Oort FJ, et al. Predicting and preventing physician burnout: results from the United States and the Netherlands. Am J Med. 2001;111:170-5. CrossRef

3. Shanafelt TD, Hasan O, Dyrbye LN, et al. Changes in burnout and satisfaction with work-life balance in physicians and the general US working population between 2011 and 2014. Mayo Clin Proc. 2015;90:1600-13. CrossRef

4. Han S, Shanafelt TD, Sinsky CA, et al. Estimating the attributable cost of physician burnout in the United States. Ann Intern Med. 2019;170:784-90. CrossRef

5. Ahola K, Honkonen T, Pirkola S, et al. Alcohol dependence in relation to burnout among the Finnish working population. Addiction. 2006;101:1438-43. CrossRef

6. Martin F, Poyen D, Bouderlique E, et al. Depression and burnout in hospital health care professionals. Int $J$ Occup Environ Health. 1997;3:204-9. CrossRef

7. Dyrbye LN, Thomas MR, Massie FS, et al. Burnout and suicidal ideation among U.S. medical students. Ann Intern Med. 2008;149:334-41. CrossRef

8. Demerouti E, Demerouti E, Bakker AB, Vardakou I, Kantas A. The convergent validity of two burnout instruments. Eur $J$ Psychol Assess. 2003;19:12-23. 
9. Hartzband P, Groopman J. Physician burnout, interrupted. N Engl J Med. 2020;382:2485-7. CrossRef

10. Tawfik DS, Profit J, Morgenthaler TI, et al. Physician burnout, well-being, and work unit safety grades in relationship to reported medical errors. Mayo Clin Proc. 2018;93:1571-80. CrossRef

11. Shanafelt TD, Balch CM, Bechamps G, et al. Burnout and medical errors among American surgeons. Ann Surg. 2010;251:995-1000. CrossRef

12. Chen KY, Yang CM, Lien CH, et al. Burnout, job satisfaction, and medical malpractice among physicians. Int J Med Sci. 2013;10:1471-8. CrossRef

13. Garrouste-Orgeas M, Perrin M, Soufir L, et al. The Iatroref study: medical errors are associated with symptoms of depression in ICU staff but not burnout or safety culture. Intensive Care Med. 2015;41:273-84. CrossRef

14. Windover AK, Martinez K, Mercer MB, Neuendorf K, Boissy A, Rothberg MB. Correlates and outcomes of physician burnout within a large academic medical center. JAMA Intern Med. 2018;178:856-8. CrossRef

15. Ratanawongsa N, Roter D, Beach MC, et al. Physician burnout and patient-physician communication during primary care encounters. J Gen Intern Med. 2008;23:1581-8. CrossRef

16. Chang BP, Carter E, Ng N, Flynn C, Tan T. Association of clinician burnout and perceived clinician-patient communication. Am J Emerg Med. 2018;36:156-8. CrossRef

17. Dang BN, Westbrook RA, Black WC, Rodriguez-Barradas MC, Giordano TP. Examining the link between patient satisfaction and adherence to HIV care: a structural equation model. PLoS One. 2013;8(1):e54729. CrossRef

18. Lobo Prabhu K, Cleghorn MC, Elnahas A, et al. Is quality important to our patients? The relationship between surgical outcomes and patient satisfaction. BMJ Qual Saf. 2018;27:48-52. CrossRef

19. Patterson BM, Eskildsen SM, Clement RC, et al. Patient satisfaction is associated with time with provider but not clinic wait time among orthopedic patients. Orthopedics. 2017;40:43-8. CrossRef
20. Alarcon-Ruiz CA, Heredia P, Taype-Rondan A. Association of waiting and consultation time with patient satisfaction: secondary-data analysis of a national survey in Peruvian ambulatory care facilities. BMC Health Serv Res. 2019;19(1):439. CrossRef

21. Peterson U, Demerouti E, Bergström G, Samuelsson M, Asberg M, Nygren A. Burnout and physical and mental health among Swedish healthcare workers. J Adv Nurs. 2008;62:84-95. CrossRef

22. Williams RL. A note on robust variance estimation for clustercorrelated data. Biometrics. 2000;56:645-6. CrossRef

23. Azam K, Khan A, Alam MT. Causes and adverse impact of physician burnout: a systematic review. J Coll Physicians Surg Pak. 2017;27:495-501.

24. Hall JA, Stein TS, Roter DL, Rieser N. Inaccuracies in physicians' perceptions of their patients. Med Care. 1999;37:1164-8. CrossRef

25. Quintana JM, González N, Bilbao A, et al. Predictors of patient satisfction with hospital health care. BMC Health Serv Res. 2006;6:102. CrossRef

26. Diwan W, Nakonezny PA, Wells J. The effect of length of hospital stay and patient factors on patient satisfaction in an academic hospital. Orthopedics. 2020;43:373-9. CrossRef

27. Lehrich BM, Goshtasbi K, Brown NJ, et al. Predictors of patient satisfaction in spine surgery: a systematic review. World Neurosurg. 2020 Nov 28. [Epub ahead of print].

28. Bélanger L, Bussiéres S, Rainville F, Coulombe M, Desmartis M. Hospital visiting policies - impacts on patients, families and staff: a review of the literature to inform decision making. J Hosp Adm. 2017;6:51-62. CrossRef

(C) 2021 Advocate Aurora Health, Inc. 